\title{
Estudo Retrospectivo de 76 Fetos de Mães com Lúpus Eritematoso Sistêmico (LES) $\left.{ }^{*}\right)$
}

\section{Retrospective Study of 76 Fetus of Mother with Systemic Lupus Erythematosus (SLE)}

\author{
Marcela Ushida ${ }^{(1)}$, André Gustavo Cunha Trolezi ${ }^{(2)}$ e Emilia Inoue Sato ${ }^{(3)}$
}

\section{RESUMO}

Objetivo: avaliar a freqüência de lúpus neonatal, prematuridade, natimortalidade, abortamento e baixo peso em gestações de pacientes com LES atendidas num serviço terciário. Métodos: estudo retrospectivo dos atendimentos a pacientes com LES realizados no centro obstétrico do Hospital São Paulo/Unifesp/ EPM, entre novembro de 1991 e abril de 2003. Os dados clínicos e laboratoriais referentes à mãe e fetos foram obtidos através da revisão de prontuários médicos. Resultados: foram identificadas 60 mulheres com LES que tiveram 75 gestações. A média de

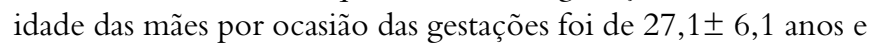
a mediana de tempo da doença foi de 48 meses. Duas gestantes necessitaram de diálise peritoneal. Sessenta e três pacientes fizeram uso de prednisona, 4 pacientes receberam pulsoterapia com solumedrol e 2 receberam azatioprina durante a gravidez. No primeiro trimestre da gestação, 6 pacientes haviam feito uso de difosfato de cloroquina e 2 utilizaram hidroxicloroquina. Uma paciente que havia recebido pulso de ciclofosfamida e outra que havia utilizado metotrexato desconhecendo a gravidez evoluíram com abortamento fetal espontâneo. Foram encontrados 13 óbitos intra-uterinos e 7 abordamentos. O parto foi prematuro em $57 \%$ das gestações e a média de tempo de gestação foi de 35 semanas. A média de peso ao nascer foi de $2.332 \pm 961 \mathrm{~g}$ (variando de 525 a $3.620 \mathrm{~g})$. Foram detectados 5 casos de lúpus neonatal $(8,9 \%)$, sendo um bloqueio cardíaco congênito (BCC) com óbito intrauterino na $29^{\mathrm{a}}$ semana e 3 plaquetopenias associadas à anti-Ro/ SSA e 1 neutropenia associada ao anti-RNP. Com exceção do caso com BCC, estes anticorpos foram detectados no soro materno e no sangue do cordão umbilical. Ao final do estudo, foram detectados dois óbitos de recém-nascidos, com 9 e 130 dias de vida, em decorrência de complicações com a prematuridade.

\begin{abstract}
Objective: to evaluate the frequency of neonatal lupus, prematurity, fetal loss, and low weight in pregnancies of SLE patients attended at a tertiary health service. Methods: it is a retrospective study evaluating all SLE patients attended at obstetric center of Hospital São Paulo/Unifesp/EPM from November, 1991 to April, 2003. The mother and children's clinical and laboratory data were obtained reviewing medical records. Results: sixty women and 75 pregnancies were identified. The mother age average during the pregnancies was $27.1 \pm 6.1$ years old and the median of disease duration was 48 months. Two patients needed to be submitted to dialysis during the pregnancy. Sixty-three patients used prednisone, 4 received methilprednisolone pulsetherapy and 2 received azathioprine during the pregnancy. During the first trimester of pregnancy, 6 patients received diphosphate chloroquine and 2 received hidroxychloroquine. Two patients unknowing pregnancy received pulse of cyclophosphamide and another one had used methotrexate and both presented spontaneous abortion. It was observed 13 cases of intrauterine death and 7 abortions. Preterm birth occurred in 57\% of pregnancies and the average duration of gestation was 35 weeks. The mean weight of the newborns was 2,332 $\pm 961 \mathrm{~g}$ (ranging from 525 to 3,620g). Five cases of neonatal lupus were identified (8,9\%). One with congenital heart block (CHB) had intrauterine death at the $29^{\text {th }}$ week of gestation, had 3 babies with thrombocytopenia associated with anti-Ro/SSA antibodies and one with neutropenia associated with anti-RNP antibody. Excepting the case of $\mathrm{CHB}$ with intrauterine death, these antibodies were detected on maternal and newborn blood sample. At the end of the study, it was detected two deaths of children with 9 and 130 days of life, due to complications related to prematurity.
\end{abstract}

\footnotetext{
* Disciplina de Reumatologia da Escola Paulista de Medicina, Universidade Federal de São Paulo (Unifesp/EPM), São Paulo, Brasil. Recebido em 6/5/2004. Aprovado, após revisão, em 16/5/2004.

1. Estudante de Medicina na Unifesp/EPM. Bolsista PIBIC-CNPq.

2. Residente de Reumatologia na Unifesp/EPM.

3. Professora titular da disciplina de Reumatologia da Unifesp/EPM.
}

Endereşo para correspondência: Emilia Inoue Sato. R. Botucatu 740, CEP 04023 900, São Paulo-SP, Brasil. E-mail: emiliasato@reumato.epm.br 
Conclusões: com relação à literatura, este estudo mostrou similar prevalência de perda fetal (aborto e óbito intra-uterino), entretanto, a frequiência de prematuridade foi maior que a média referida em outros trabalhos. Manifestações hematológicas do lúpus neonatal, como leucopenia e plaquetopenia foram observadas em freqüência maior do que a referida na literatura. Por serem transitórias e assintomáticas, estas alterações podem ter sido subdiagnosticadas.

Palavras-chave: lúpus neonatal, anticorpo anti-Ro/SS-A, anticorpo anti-La/SS-B, bloqueio cardíaco congênito.

\section{INTRODUÇÃO}

Apesar de a atividade do LES e seu tratamento estarem associados com amenorréia secundária, irregularidade menstrual e insuficiência ovariana prematura, a fertilidade nas pacientes com LES geralmente é comparável à da população controle, fazendo com que o binômio gestação e LES seja relativamente freqüente nos serviços que atendem estas pacientes ${ }^{(2,3)}$.

Diversos fatores relacionados com a doença ou com o seu tratamento podem influenciar a evolução da gestação, assim como alterações decorrentes da gravidez podem influenciar a evolução da doença. Além disso, anticorpos relacionados com o LES, como os anticorpos antifosfolípides, conferem risco aumentado de abortamento e prematuridade ${ }^{(4,5)}$.

O lúpus neonatal é uma manifestação decorrente da passagem transplacentária de auto-anticorpos maternos (anti-Ro/SSA e anti-La/SSB e mais raramente Anti-U1RNP) ${ }^{(6-8,12,13)}$, podendo ocasionar bloqueio cardíaco congênito, lesões cutâneas, citopenias e mais raramente hepatopatias nos fetos ${ }^{(8,9,14)}$.

O objetivo deste estudo foi o de avaliar retrospectivamente a freqüência de lúpus neonatal, prematuridade, baixo peso e perda fetal em gestações de pacientes com LES atendidas num serviço terciário.

\section{PACIENTES E MÉTODOS}

Através da revisão dos registros de atendimento do centro obstétrico do HSP/Unifesp/EPM, no período de novembro de 1991 a abril de 2003, foram identificadas 80 pacientes com diagnóstico de LES. Foram excluídos da análise 11 casos que não preenchiam critérios de classificação para LES $^{(1)}$ e 9 casos cujos prontuários médicos não foram encontrados. Os registros dos recém-nascidos foram encontrados no livro de atendimento da Neonatologia. Os prontuários das mães e dos recém-nascidos foram revistos para obtenção
Conclusions: comparing with published reports this study showed a similar frequency of fetal loss (abortion and intrauterine death), however the frequency of prematurity was higher than the mean reported in the literature. Hematological features of neonatal lupus, as leucopenia and thrombocytopenia were observed at higher frequency than reported in the literature. As transitory and asymptomatic features, they could have been under-diagnosed.

Keywords: neonatal lupus, anti-Ro/SS-A antibody, anti-La/SS-B antibody, congenital heart block.

de dados clínicos e laboratoriais inseridos em banco de dados utilizando o aplicativo Excel.

A prematuridade foi definida como a idade gestacional menor que 37 semanas, e as perdas fetais como a soma de óbitos fetais e abortamentos. A hipertensão arterial foi definida como pressão arterial $\geq 140 \times 90 \mathrm{mmHg}$, ou uso de medicamentos anti-hipertensivos. Foi considerado como tempo de doença o tempo entre o diagnóstico de LES e a data da gestação. Para estudar possível associação entre as manifestações clínicas e laboratoriais e a evolução da gestação, foram consideradas as alterações presentes no início e no final da gestação.

Análise estatística - O programa estatístico SPSS 8.0 para Windows foi utilizado para a análise estatística. O teste $\mathrm{X}^{2}$ de Pearson e o teste exato de Fisher foram utilizados para avaliar a possível associação entre prematuridade ou perda fetal e as variáveis categóricas (doença hipertensiva específica da gravidez, hipertensão arterial, pré-eclampsia, comprometimento renal, hematológico, cutâneo e articular em diferentes fases da gestação) e o teste $t$ de Student para comparar as variáveis hemoglobina/hematócrito (Hb/Htc) e prematuridade ou óbito fetal. Foram considerados estatisticamente significantes valores de $\mathrm{p}<0,05$ e considerada tendência a serem significantes valores de $p$ entre 0,05 e 0,1 .

\section{RESULTADOS}

Foram avaliadas 75 gestações de 76 fetos (uma gestação gemelar) de 60 mulheres com LES. Destas, 20 resultaram em morte do concepto (13 óbitos fetais e 7 abortamentos, sendo um abortamento provocado) e 56 nascidos vivos.

Dados maternos e das gestações - A média da idade das mães por ocasião da gestação foi de $27 \pm 6,22$ anos (variando de 15 a 41 anos), a mediana do tempo de doença do LES foi de 48 meses, variando de 1 a 240 meses. 
A Tabela 1 mostra os resultados da pesquisa de autoanticorpos ao longo da evolução do LES.

Do total de 75 gestações, 16 (21,3\%) apresentaram doença hipertensiva específica da gravidez (DHEG) e $5(6,6 \%)$ apresentaram pré-eclampsia. Somente três pacientes que apresentaram DHEG tinham anticorpos anticardiolipina e nenhuma das pacientes que desenvolveram pré-eclampsia apresentaram anticorpo anticardiolipina. Foi observada associação significante entre DHEG e prematuridade $(75,0 \%$ vs $44,2 \% ; \mathrm{p}=0,038)$, e, entre acometimento renal no início da gravidez e prematuridade $(71,4 \%$ vs $40,54 \% ; \mathrm{p}=0,032)$. Houve tendência à associação entre prematuridade e aumento de creatinina no início da gestação $(83,3 \%$ vs $48,7 \%$; $p=0,07)$.

Foi observada associação significante entre presença de vasculite no início da gestação e perda fetal $(80,0 \%$ vs $20,9 \%$; $\mathrm{p}=0,012)$ e entre anticorpo anti-DNA nativo no final da gestação e perda fetal $(57,1 \%$ vs $18,6 \%$; $p=0,044)$. Associação significante também foi encontrada entre vasculite no final da gestação e perda fetal (71,4\% vs $22,1 \%$; $p=0,012$ - Fisher).

Cinco pacientes que apresentavam creatinina $\geq 1,2 \mathrm{mg} / \mathrm{dl}$ em consulta no início da gravidez apresentaram níveis séricos de creatinina normais ao final da mesma. Entretanto, cinco outras pacientes com nefrite apresentaram dosagens de creatinina anormal $(1,2$ a $3,5 \mathrm{mg} / \mathrm{dl})$ no final da gravidez e duas necessitaram de diálise peritonial durante a gestação. Embora nenhuma das gestantes submetidas à diálise peritoneal tenha apresentado perda fetal, ambas tiveram filhos prematuros (idade gestacional de 27 e 34 semanas). Após a gestação, ambas evoluíram com insuficiência renal crônica, sendo que uma delas iniciou tratamento hemodialítico no puerpério e a outra está sendo mantida em tratamento conservador.

As pacientes fizeram uso de prednisona durante 63 gestações. Quatro pacientes receberam pulsoterapia com solumedrol, duas das quais também fizeram uso de azatioprina durante a gravidez. No primeiro trimestre da gestação, seis pacientes haviam feito uso de difosfato de cloroquina e duas utilizaram hidroxicloroquina. Uma paciente recebeu ciclofosfamida na forma de pulso (um ciclo) e outra paciente fez uso de metotrexato no início da gestação, por não saberem que estavam grávidas. Ambas evoluíram com abortamento espontâneo no primeiro trimestre.
Dados dos fetos - Entre os nativivos, 37 nasceram de parto cesárea $(66,1 \%)$ e 19 de partos vaginais $(33,9 \%)$. Dezesseis fetos $(28,5 \%)$ tiveram sofrimento fetal diagnosticado antes do parto. Trinta e seis eram do sexo masculino e 20 do feminino. Quarenta e seis recém-nascidos tinham peso adequado para a idade gestacional (AIG) e 10 eram pequenas para idade gestacional (PIG). Vinte e nove RN eram prematuros e tinham baixo peso ao nascer $(<2.500 \mathrm{~g})$. Quatro recém-nascidos apresentaram extremo baixo peso $(<1.000 \mathrm{~g})$. A Figura 1 mostra a distribuição do peso dos RN e a Figura 2 mostra distribuição dos RN de acordo com a idade gestacional.

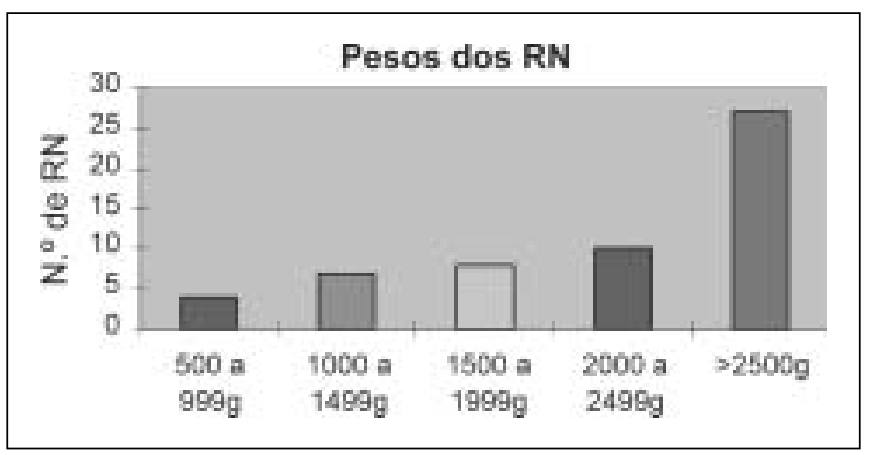

Figura 1 - Distribuição do peso (em gramas) dos recém-nascidos.

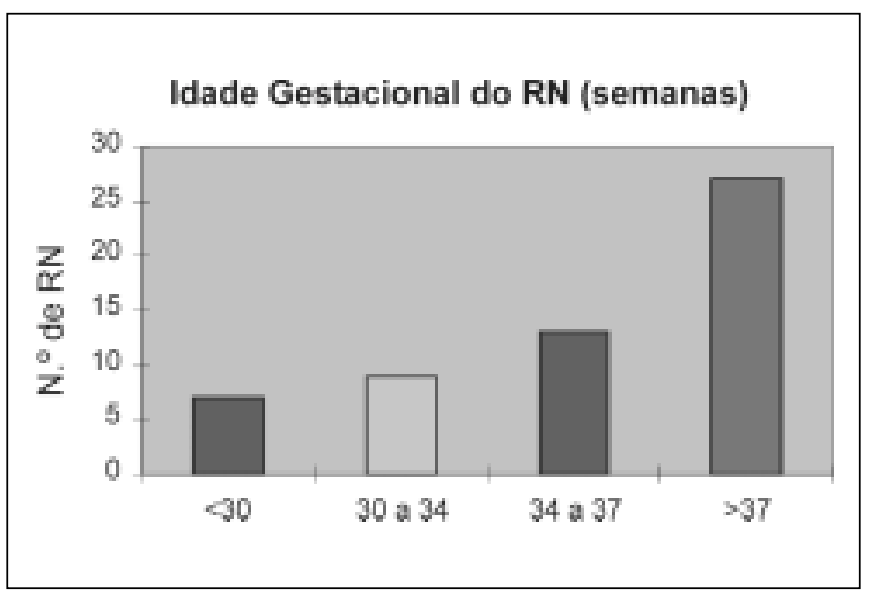

FIguRa 2 - Distribuição da idade gestacional (em semanas) dos recémnascidos.

TABela 1

AutO-ANTICORPOS MATERNOS AO LONGO DA EVOLUÇÃO DO LES

\begin{tabular}{lcccccc}
\hline FAN & Anti-DNA & Anti-Sm & Anti-Ro/SSA & Anti-SSB/La & Anti-U1-RNP & anticardiolipina \\
\hline $100 \%$ & $46,67 \%$ & $26,67 \%$ & $41,67 \%$ & $16,67 \%$ & $35,0 \%$ & $18,18 \%$ \\
& & & & & & $(10 / 55)$ \\
\hline
\end{tabular}


Foi observada associação significante entre presença de hipertensão arterial antes da gravidez e fetos com baixo peso $(73,3 \%$ vs $42,9 \%$; $\mathrm{p}=0,032)$. Foi observada uma tendência à associação entre presença de hipertensão arterial no final da gestação e RN de baixo peso ( $68,4 \%$ vs $40,0 \%$; $\mathrm{p}=0,06)$.

Foi encontrada também associação significante entre altos níveis de creatinina materna antes da gestação e baixo peso $(\mathrm{p}=0,033)$ e baixos valores de $\mathrm{Hb}$ ou Htc no final da gestação com baixo peso dos RNs ( $p=0,013$ e $p=0,011$ respectivamente).

Uma gestante com anticorpo anti-Ro/SSA positivo, mas anti-La/SSB negativo, primigesta, que não fazia acompanhamento no Hospital São Paulo foi internada na $27^{\mathrm{a}}$ semana de gestação, em decorrência de bradicardia fetal, sendo diagnosticado bloqueio atrioventricular total no ecocardiograma fetal. O feto sofreu óbito intra-uterino na $29^{a}$ semana de gestação.

Evolução dos RNs - A mediana do tempo de internação dos RNs foi de 5 dias, variando de 2 a 290 dias. Os 11 RNs que tiveram tempo de internação maior que 30 dias eram prematuros e, destes, 8 apresentaram infecção durante a internação.

$\mathrm{Na}$ enfermaria neonatal 11 crianças desenvolveram infecções, principalmente por bactérias Gram-negativas. A mediana de permanência dos $21 \mathrm{RNs}$ em isolete foi de 20 dias, variando de 1 a 158 dias.

Houve necessidade de ventilação mecânica em 8 RNs. Dezoito RNs apresentaram algum tipo de comprometimento pulmonar (taquipnéia transitória, síndrome do desconforto respiratório e síndrome de escape de ar), 9 RNs apresentaram acometimento neurológico (hemorragia peri/intraventricular, convulsões), 7 tiveram necessidade de transfusão sangüínea e 5 RNs tiveram acometimento ocular.

$\mathrm{Na}$ evolução, foram encontrados 1 caso de sífilis congênita, 1 caso de osteomielite na cabeça do úmero, 1 BIRD (bloqueio incompleto do ramo direito) em feto de mãe com sorologia negativa para anticorpos anti-Ro/SSA, anti$\mathrm{La} / \mathrm{SSB}$ ou anti-U1-RNP e 1 caso de nefrocalcinose.

Ocorreram apenas dois óbitos entre os 56 fetos que nasceram vivos. Os dois óbitos foram de gêmeos dizigotos, prematuros de 26 semanas e 4 dias que faleceram no nono e no $130^{\circ}$ dia de vida, em conseqüência de uma infecção pulmonar. A mãe havia desenvolvido o LES durante a gestação, tendo evoluído com comprometimento renal e grave hipertensão arterial. Foi indicada cesárea, pois foi detectado sofrimento fetal de um dos gêmeos. Após o parto, houve controle da hipertensão arterial e melhora da função renal materna.
Lúpus neonatal - Neste estudo, foram diagnosticados 5 casos de lúpus neonatal entre 76 gestações $(6,6 \%)$. Um caso de bloqueio cardíaco completo com óbito fetal intrauterino, 3 casos de plaquetopenia e 1 caso com neutropenia.

Dois RNs, de duas diferentes gestações, de uma mãe com anticorpos anti-Ro/SSA e anti-La/SSB positivos apresentaram plaquetopenia. Outro RN de mãe apenas com anti-Ro/SSA positivo apresentou plaquetopenia e aumento de transaminases. Nos três casos o anticorpo anti-Ro/SSA estava presente e o anti-La/SSB ausente no sangue dos RNs.

Um RN apresentou neutropenia e anticorpos anti-U1RNP foram identificados no soro materno e no sangue do RN. Mãe e RN não apresentavam anticorpos anti-Ro/ SSA e anti-La/SSB.

Quatro outros RNs apresentaram plaquetopenia. Em três casos as mães tinham anti-Ro/SSA, associado à anti-La/SSB em uma e à anti-U1-RNP e anti-Sm em duas pacientes. Em um caso, a mãe apresentava anti-U1-RNP, sem anti-Ro ou anti-La. Nestes quatro casos não foram encontrados os resultados da pesquisa de auto-anticorpos no sangue do cordão umbilical ou dos recém-nascidos, para se confirmar o lúpus neonatal como possível causa da alteração hematológica nos recém-nascidos. Em todos os casos as alterações hematológicas foram transitórias e os auto-anticorpos nos recém-nascidos negativaram durante o seguimento.

\section{DISCUSSÃO}

O lúpus neonatal, decorrente da passagem transplacentária de imunoglobulinas maternas (anti-Ro/SSA, anti-La/SSB e anti$\mathrm{RNP})^{(5-7)}$, pode ocorrer em gestantes com qualquer doença associadas a estes auto-anticorpos (LES, síndrome de Sjögren e outras doenças reumáticas) e em mulheres assintomáticas ${ }^{(11)}$.

Segundo dados do Registro de Pesquisa para o Lúpus Neonatal do Instituto Nacional de Artrites e Doenças Musculoesqueléticas e Cutâneas de Nova York, 64\% dos neonatos tinham bloqueio cardíaco congênito, 31\% tiveram lesões cutâneas, 4,3\% bloqueio cardíaco com lesões cutâneas e 2,4\% tiveram outras manifestações do lúpus neonatal.

Além do bloqueio cardíaco (a manifestação mais grave do lúpus neonatal) e das lesões cutâneas transitórias, que surgem geralmente entre o segundo e o terceiro meses de vida, anormalidades hematológicas como anemia, neutropenia, plaquetopenia e envolvimento hepático também têm sido descritos ${ }^{(8-11)}$.

A freqüência do bloqueio cardíaco congênito (BCC) em nosso estudo (1,3\% das gestações e 4,1\% das gestantes com anti-Ro/SSA) foi semelhante ao da literatura, que relata 
prevalência estimada em 1 para 20.000 nascimentos $(0,005 \%)$ na população geral, e, de $1 \%$ a $2 \%$ dos fetos de pacientes com LES e de $5 \%$ em gestantes com LES e anticorpos anti-Ro/SSA ${ }^{(14,17)}$.

Não encontramos nos prontuários dos RNs nenhuma descrição de lesões cutâneas sugestivas de lúpus neonatal; entretanto, lembramos que sendo um estudo retrospectivo, as lesões cutâneas podem ter sido subdiagnosticadas.

Apesar de a literatura demonstrar a ocorrência de trombocitopenia e neutropenia em torno de $5 \%$ a $10 \%$ dos casos de lúpus neonatal ${ }^{(14)}$, na maioria das vezes estas alterações foram relatadas em recém-nascidos que apresentavam concomitantemente outras manifestações do lúpus neonatal, como o bloqueio cardíaco congênito e as lesões cutâneas.

Em nosso estudo, os quatro casos com alterações hematológicas, exceto um que também apresentou aumento de transaminases, não evoluíram com outras manifestações do lúpus neonatal. As alterações hematológicas foram atribuídas ao lúpus neonatal apenas nos casos em que anticorpos antiRo/SSA ou anti-U1-RNP haviam sido detectados no soro materno e no sangue do cordão umbilical ou do recémnascido. Estes achados sugerem que estas manifestações podem ser mais freqüentes do que as descritas, sendo subdiagnosticadas por não apresentarem significado clínico, uma vez que são alterações laboratoriais transitórias.

Encontramos $34 \%$ de perdas fetais e $52 \%$ de prematuridade em nossa série, sendo a DHEG e o acometimento renal as variáveis associadas à prematuridade, como já referido em outras séries da literatura. Interessante o encontro de associação significativa entre presença de vasculite e perda fetal, assim como a presença de anticorpos anti-DNA e perda fetal. Estes dados reforçam a necessidade de a atividade do lúpus estar bem controlada para que a gestação tenha uma boa evolução, assim como demonstra a importância da hipertensão arterial e da função renal na evolução da gravidez e no prognóstico fetal.

A falta de associação significante entre pré-eclampsia e prematuridade deve-se provavelmente ao pequeno número de gestações em que esta complicação se apresentou no presente estudo.

\section{REFERÊNCIAS}

1. Tan EM, Cohen AS, Fries JF, et al: The 1982 revised criteria for the classification of systemic lupus erythematosus. Arthritis Rheum 25:1271-7, 1982.

2. Mok CC, Wong RWS: Pregnancy in systemic lupus erythematosus. Postgrad Med J 77:157-65, 2001.
Apesar de o prognóstico de mulheres gestantes com LES ter melhorado muito nos últimos anos, ainda continua relativamente alta a freqüência de prematuridade e perdas fetais (abortamentos e óbitos intra-uterinos). A freqüência das perdas fetais tem sido descrita em torno de $8 \%$ a $43 \%$ em séries retrospectivas e de $11 \%$ a $24 \%$ em séries prospectivas $^{(14-16)}$. A incidência de prematuridade varia de $17 \%$ a $49 \%{ }^{(14,16)}$, sendo a atividade do LES e a hipertensão arterial os maiores preditores deste evento. No presente estudo não pudemos avaliar a freqüência destes eventos, pois foram analisadas apenas as gestantes com LES atendidas no centro obstétrico do Hospital São Paulo. Algumas pacientes com LES de nosso serviço podem ter sido atendidas em outros centros obstétricos.

Um bom serviço de neonatologia é fundamental para o prognóstico das crianças nascidas de mães com LES, muito freqüentemente prematuras e com baixo peso. $\mathrm{O}$ encontro de apenas dois óbitos entre os 56 nativivos, muitos dos quais com extremo baixo peso, atesta o excelente nível do atendimento neonatal prestado no Hospital São Paulo.

Este estudo mostra freqüência de BCC, prematuridade e perda fetal comparável ao referido em estudos retrospectivos realizados em outros países. Diferente do reportado na literatura, encontramos quatro recém-nascidos que apresentaram alterações hematológicas compatíveis com lúpus neonatal sem outros comprometimentos como BCC ou lesões cutâneas. Estas alterações foram transitórias e não houve necessidade de tratamento específico. Muito provavelmente estas anormalidades são subdiagnosticadas.

\section{AGRADECIMENTOS}

Agradecemos à dra. Gianna Mastroianni Kirsztain, responsável pelo setor de Nefrites da disciplina de Nefrologia e à dra. Amélia Miyashiro Nunes dos Santos, chefe da disciplina de Pediatria Neonatal a colaboração na obtenção dos dados das pacientes e recém-nascidos. Agradecemos também ao Fundo de Auxílio à Pesquisa e Ensino em Reumatologia da SBR o suporte financeiro e ao CNPq a bolsa de iniciação científica.

3. Kaufman RL, Kitridou RC: Pregnancy in mixed connective tissue disease: comparison with systemic lupus erythematosus. J Rheumatol 9:549-55, 1982.

4. Hayslett JP: The effect of systemic lupus erythematosus on pregnancy and pregnancy outcome. Am J Reprod Immunol 28:199-204, 1992.

5. Le Huong D, et al: Outcome of planned pregnancies in systemic lupus erythematosus: a prospective study on 62 pregnancies. $\mathrm{Br} \mathrm{J}$ Rheumatol 36:772-7, 1997. 
6. Tran HB, Macardle PJ, Hiscock J, et al: Anti-La/SSB antibodies transported across the placenta bind apoptotic cells in fetal organs targeted in neonatal lupus. Arthritis Rheum 46:1572-9, 2002.

7. Miyagawa S, Dohi K, Yoshioka A, Shirai T: Female predominance of immune response to SSA/Ro antigens and risk of neonatal lupus erythematosus. Br J Dermatol 123:223-7, 1990.

8. Askanase AD, Friedman DM, Copel J, et al: Spectrum and progression of conduction abnormalities in infants born to mothers with antiSSA/Ro-SSB/La antibodies. Lupus 11:145-51, 2002.

9. Kanagasegar S, Cimaz R, Kurien BT, Brucato A, Scofield RH: Neonatal lupus manifests as isolated neutropenia and mildly abnormal liver functions. J Rheumatol 29:187-91, 2002.

10. Ramsey-Goldman R, Hom D, Deng JS, et al: Anti-SS-A antibodies and fetal outcome in maternal systemic lupus erythematosus. Arthritis Rheum 29:1269-73, 1986.

11. Brucato A, Doria A, Frassi M, et al: Pregnancy outcome in 100 women with autoimmune diseases and anti-Ro/SSA antibodies: a prospective controlled study. Lupus 11: 716-21, 2002.
12. Sheth AP, Esterly NB, Ratoosh SL, Smith JP, Hebert AA, Silverman E: U1RNP positive neonatal lupus erythematosus: association with anti-La antibodies? Br J Dermatol 132:520-6, 1995.

13. Su CT, Huang CB, Chung MY: Neonatal lupus erythematosus in association with anti-RNP antibody: a case report. Am J Perinatol 18:421-6, 2001.

14. Kitridou RC, Mintz G: Pregnancy in lupus: the mother in SLE. The fetus in SLE. The Neonatal Lupus syndrome. In: Dubois EL, Wallace J. Eds. Lupus erythematosus, 6th ed, 2002.

15. Watson RM, Braunstein BL, Watson AJ, Hochberg MC, Provost TT: Fetal wastage in women with anti-Ro (SSA) antibody. J Rheumatol 13:90-4, 1986.

16. Mintz G, Niz J, Gutierrez G, Garcia-Alonso A, Karchmer S: Prospective study of pregnancy in systemic lupus erythematosus. Results of a multidisciplinary approach. J R heumatol 13:732-9, 1986.

17. Ramsey-Goldman R, Hom D, Deng JS, et al: Anti-SS-A antibodies and fetal outcome in maternal systemic lupus erythematosus. Arthritis Rheum 29:1269-73, 1986. 